\title{
Can you make a boat?
}

\author{
Alejandra Escovar ${ }^{1}$ \\ ${ }^{1}$ Journal of Conceptual and Applied STEM Education
}

September 2, 2020

\section{Summary:}

K-2 Students will review the steps and importance of the Engineering Design Process through and engineering design challenge. They must make a boat that will travel to the other side of a test tank safely.

\section{Key words:}

Engineer, problem, define, constraint, solution, prototype, test, improve, sink, float.

\section{Learning Outcomes:}

After the students complete this challenge they should be able to:

- Describe the different steps of the Engineering Design Process (EDP)

- Describe how engineers find the solutions to problems and make use of the materials they have around

- Describe their experience and the steps they took to solve the challenge using the EDP

\section{Standards:}

Next Generation Science Standards

K-2-ETS1-1. Ask questions, make observations, and gather information about a situation people want to change to define a simple problem that can be solved through the development of a new or improved object or tool.

ETS1.A: Defining and Delimiting Engineering Problems:

- A situation that people want to change or create can be approached as a problem to be solved through engineering.

- Asking questions, making observations, and gathering information are helpful in thinking about problems.

- Before beginning to design a solution, it is important to clearly understand the problem.

K-2-ETS1-2. Develop a simple sketch, drawing, or physical model to illustrate how the shape of an object helps it function as needed to solve a given problem.

ETS1.B: Developing Possible Solutions:

- Designs can be conveyed through sketches, drawings, or physical models. These representations are useful in communicating ideas for a problem's solutions to other people. 
K-2-ETS1-3. Analyze data from tests of two objects designed to solve the same problem to compare the strengths and weaknesses of how each performs.

ETS1.C: Optimizing the Design Solution:

- Because there is always more than one possible solution to a problem, it is useful to compare and test designs.

ISTE Standards

\section{Empowered Learner}

1a- Students articulate and set personal learning goals, develop strategies leveraging technology to achieve them and reflect on the learning process itself to improve learning outcomes.

1d- Students understand the fundamental concepts of technology operations, demonstrate the ability to choose, use and troubleshoot current technologies and are able to transfer their knowledge to explore emerging technologies.

\section{Knowledge Constructor}

3a- Students plan and employ effective research strategies to locate information and other resources for their intellectual or creative pursuits.

\section{Computational Thinking}

5b- Students collect data or identify relevant data sets, use digital tools to analyze them, and represent data in various ways to facilitate problem-solving and decision- making.

5c- Students break problems into component parts, extract key information, and develop descriptive models to understand complex systems or facilitate problem-solving.

\section{Introduction:}

In order to review or evaluate the students' understanding of the EDP first and second grade students will be presented with a challenge. The teacher will present a problem for the students by making up a story about a character that did not know how to swim but needed to cross a river. The teacher may use a toy animal or Lego character as the main character in the story.

Students will be faced with the challenge. They have to create a "boat" that will help the character cross the river safely. The teacher will also present the constraints that the boat will have, as well as the rubric for the group evaluation. Students will be paired up in teams and will be sent off to work. A key point is that they must show evidence of following the EDP during their quest to finding the solution to the challenge.

\section{Materials:}

For the test tank:

big cardboard boxes

big trash bags

tape

For the boats:

water bottles

milk or juice cartons

foam 
balloons

straws

fabric

tape

glue

Character to be placed on the boat

\section{Procedure:}

1. Students will be presented to the character and the story. They must be able to see the character and touch it in order to know the specific measurements of the boat they need to make.

2. After students evaluate the character, they will look at the width of the box that will become the tank in order to plan ahead.

3. Students will investigate what materials can float in water by using the kid friendly search engine Kiddle.co

4. They will sketch their idea on paper, choose their materials and start creating their prototype.

5. Teacher will serve as a guide to help (if necessary) or to spark ideas by asking questions.

6. The test tank will be built by the teams that finish first. The box will be covered with the trash bag so the water won't seep through.

7. After the box is full of water, students will take turns testing their creations.

8. Once all the teams took a turn, students will talk about their creations, focus on what worked and what didn't and share ideas on ways they could improve.

\section{Evaluation:}

Students will be evaluated on teamwork, end result of their creation, and evidence of use of the Engineering Design Process.

\section{Extension:}

Students can be asked to change one thing in their prototype and see how that would affect their creation.

Students can compare their creation to real life and talk about where they got the inspiration for their design.

A current or wave can be added to the test tank to see if the prototype can still take the character to the other side safely.

Students can measure the distance traveled and the amount of time it took. 